УДК 621.398 .96

I. Р. Пархомей, В. А. Паюн, А. М. Ярич

\title{
ФРАКТАЛЬНО-РЕЗОНАНСНА СЕЛЕКЦІЯ СИГНАЛІВ БЕЗПІЛОТНИМИ АПАРАТАМИ
}

Анотація. В роботі розглянуті теоретичні основи фрактально-резонансної селекції сигналів, заснованої на використанні фрактальних властивостей шорсткуватих поверхонь випромінювання антен і резонансної взаємодії електромагнітного поля із кристалічною структурою провідника.

Ключові слова: скін-шар, фрактальна розмірність поверхні, механічні коливання кристалічної структури речовини.

\section{Вступ}

В наш час негативний вплив взаємних завад на ефективність роботи радіотехнічних систем та комплексів значно збільшився й, безумовно, буде збільшуватися і надалі. Це пов'язане не тільки зі збільшенням кількості одночасно працюючих радіоелектронних засобів, але й ще більшою мірою із широким застосуванням складних радіоелектронних комплексів. Усе більша кількість взаємних завад змушує шукати нові підходи для виділення корисних сигналів 3 апріорно заданими параметрами на тлі інших сигналів (завад). У свою чергу, велика кількість реальних фізичних систем має (у відповідних діапазонах масштабів) фрактальну природу, яка характеризується значеннями однієї або декількох відповідних фрактальних розмірностей [1-9]. Зокрема, фрактальними властивостями, які правомірно можуть бути використані для селекції корисних сигналів у радіотехнічних системах, мають поверхні шорсткуватих провідників антен. В зв'язку з цим, розглянемо елементарний випромінюючий елемент, що має циліндроподібну форму (рис. 1.1). Нехай $l_{l}$ i $l_{T}$ - його фрактальні довжини, поздовжня й поперечна (периметр), а $S$ - фрактальна площа поверхні елементарного випромінювача, укладена між поперечними перерізами, що відстоять друг від друга на відстані $l_{l}$. Для довільної фрактальної поверхні повинне, загалом кажучи, виконуватися нерівність $S \neq l_{l} \cdot l_{T}$. Припустимо, що уздовж циліндра прикладений змінний електричний потенціал з амплітудою $V$ й частотою $\omega$. Відповідна глибина скін-шару визначається виразом [10]:

$$
\delta=\sqrt{\frac{2}{\gamma \cdot \mu \cdot w}}
$$

де $\gamma, \mu$ - відповідно електропровідність та магнітна проникність речовини, які залежать від ії електромагнітних властивостей.

(c) I. Р. Пархомей, В. А. Паюн, А. М. Ярич

ISSN 1560-8956 


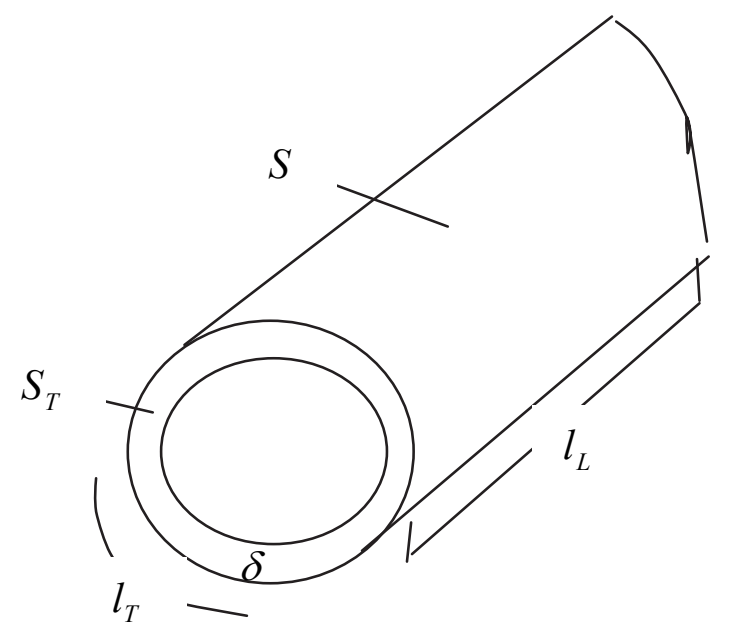

Рис. 1.1. - Зразок провідника із фрактальною зовнішньою поверхнею

Щодо рисунку: слід зазначити, що $l_{T}$ - периметр, змінний потенціал прикладений між (еквіпотенціальними) основами, а товщина скін-шару $\delta$ зображена без дотримання масштабу задля зручності перевірки фрактальності й шорсткуватості поверхні.

Фрактальні величини $l_{T}, l_{l}$ i $S$ породжують фрактальні розмірності $d_{T}, d_{l}$ й $d_{S}$, задаючи їх за допомогою співвідношень:

$$
d_{L}=\frac{\ln \left(l_{L} / \delta\right)}{\ln (1 / \delta)}
$$

звідки

$$
\begin{gathered}
l_{L}=\frac{1}{\delta^{d} S^{-1}} \\
d_{L}=\frac{\ln \left(l_{T} / \delta\right)}{\ln (1 / \delta)},
\end{gathered}
$$

звідки

$$
l_{T}=\frac{1}{\delta^{d} T^{-1}}
$$

та

$$
d_{S}=\frac{\ln \left(S / \delta^{2}\right)}{\ln (1 / \delta)}
$$

звідки

$$
S=\frac{1}{\delta^{d} S^{-2}}
$$

У загальному випадку слушні нерівності $1 \leq d_{l}, d_{T} \prec 2$ (рівність виконується для гладких дифференційних кривих) і $2 \leq d_{S} \prec 3$ (рівність виконується для гладких дифференційних поверхонь). 
Цікавий окремий випадок виникає, коли $S=l_{i} \cdot l_{T}$ : у цьому випадку $d_{s}=d_{i}+d_{T}$. Інший цікавий окремий випадок представляє (статистично) однорідна ізотропна фрактальна поверхня: у цьому випадку $d_{l}=d_{T}=d_{S}-1 \geq 1$.

Енергія $P$, що розсіюється провідною речовиною, визначається виразом:

$$
P=\int j(r) \cdot E(r) \cdot d^{3} \cdot r,
$$

де $j(r)$ - щільність струму; $E(r)$ - напруженість електричного поля в точці $r$.

За законом Ома $j(r)=\gamma E(r)$, що дозволяє описати співвідношення (5) у вигляді:

$$
P=\sigma \int E^{2} d^{3} r=\sigma\left\langle E^{2}\right\rangle_{\mathrm{CKIH}} \int d^{3} r=\sigma\left\langle E^{2}\right\rangle_{\mathrm{CKIH}} S \delta
$$

де «скін» означає обсяг $\vartheta \equiv \int{ }_{\mathrm{CKIH}} d^{3} r=s \delta$ шару речовини в якому електричне поле істотне відмінне від нуля.

Якщо проводиться експеримент із фіксованою щільністю електромагнітного поля то з виразу (6) одержуємо:

$$
p \approx S \delta=\delta^{3-d_{S}}
$$

Використовуючи співвідношення (1) вираз для потужності матиме вид:

$$
p=\frac{1}{\omega^{\frac{3-d s}{2}}}
$$

Виконавши експеримент із проходженням змінного електричного струму, одержимо $\left\langle E^{2}\right\rangle_{C K I H}=V^{2} / l_{L}^{2}$. Тоді з урахуванням співвідношення (6) маємо:

$$
P=\frac{\sigma V^{2} s \delta}{l_{L}^{2}}
$$

Порівнюючи (9) з формулою $P=V^{2} / R$ ( $R$ - електричний опір), одержуємо:

$$
R=\frac{\sigma l_{L}^{2}}{s \sigma}
$$

Нарешті, зі співвідношень ( $\left.2^{\prime}\right)$ і ( $\left.4^{\prime}\right)$, знаходимо, що:

$$
R=\sigma^{d_{s}-2 d_{L}-1}
$$

Або з урахуванням співвідношення (1):

$$
R \approx \omega \frac{1+2 d_{1}-d s}{2}
$$

При $d_{s}=2$ й $d_{L}=1$ це співвідношення буде стандартне: $R \approx \sqrt{\omega}$.

Шляхом нанесення експериментальних дних на графіки в координатах $(\ln P, \ln \omega)$ і $(\ln R, \ln \omega)$, отримуємо прямі з кутовими коефіцієнтами $\frac{\left(d_{3}-3\right)}{3}$ 
й $\frac{\left(1+3 d_{L}-d_{S}\right)}{2}$, що дозволяє безпосередньо виміряти $d_{S}$ й $d_{L}$.

При $d_{S}=d_{L}+d T$, зі співвідношень (8) і (12) одержуємо:

$$
P \approx \frac{1}{\omega \frac{3-d_{L}-d_{T}}{2}}
$$

та

$$
R \approx \omega \frac{1+d_{L}-d_{T}}{2}
$$

В іншому окремому випадку при $d_{i}=d_{T}=d_{s}-1$, зі співвідношень (8) і (12) випливає, що:

$$
P \approx \frac{1}{\omega^{\frac{2-d_{L}}{2}}},
$$

та

$$
R \approx \omega^{\frac{d_{L}}{2}}
$$

У цьому випадку один експеримент, наприклад вимір $R$, як функції від $\omega$, дозволяє визначити $d_{L}$. В експериментах обох типів (із проходженням електричного струму й фіксованою щільністю електромагнітного випромінювання в порожнині) просторовий розподіл електромагнітного струму еволюціонує із частотою $\omega$, і саме ця еволюція дозволяє полю дослідити фрактальну розмірність системи. Якісно-просторовий розподіл електромагнітного поля зовні (усередині) речовини в експерименті з фіксованою щільністю електромагнітного випромінювання в порожнині (проходження змінного електричного струму) наведений на рис. 1.2 .

Штриховою лінією показаний скін-шар у речовині при певній частоті. В експерименті з фіксованою щільністю електромагнітного випромінювання в порожнині показане електричне поле зовні провідника ( $a$ й б); в експерименті із проходженням електричного струму показане електричне поле усередині провідника (в та г).

Для реалізації фрактальної селекції необхідно встановити відповідність між значенням фрактальної площі апертури антени відповідного радіотехнічного засобу й законом зміни амплітуди сигналу у точці спостереження $P(x, y, z)$ на певних інтервалах часу (рис.3 ). 
Відносно низька $\omega$

Експериментальна залежність

$P(\omega)$

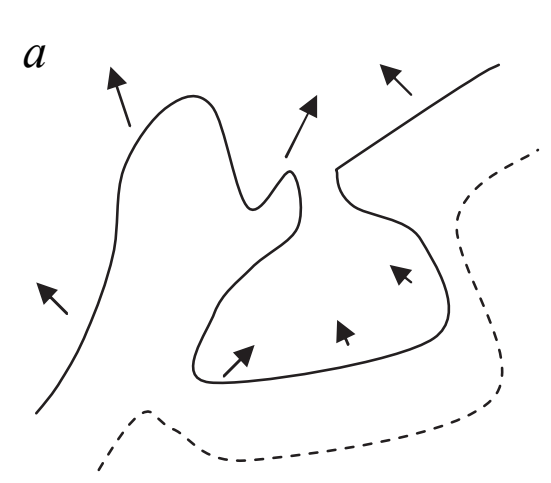

Відносно висока $\omega$

$\sigma$

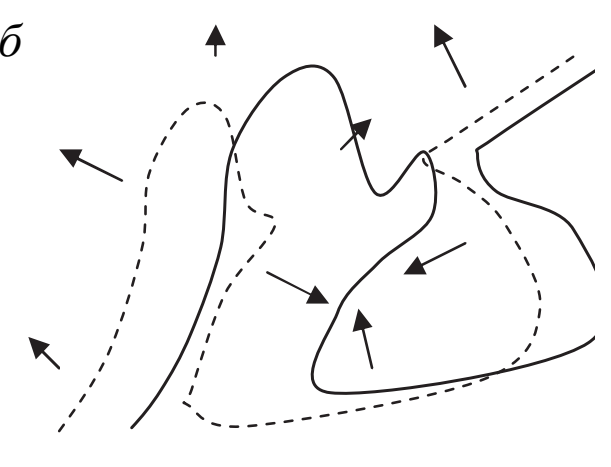

Експериментальна залежність

$R(\omega)$

B

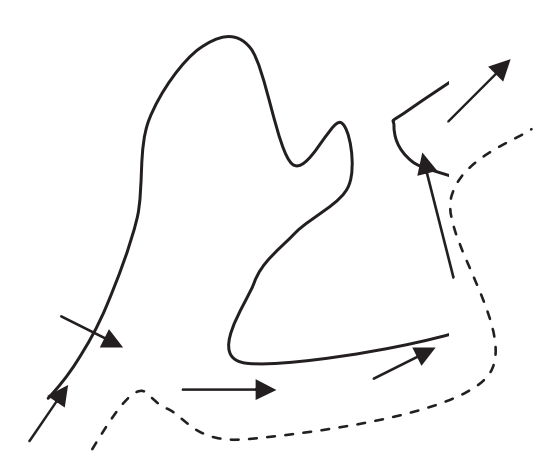

2

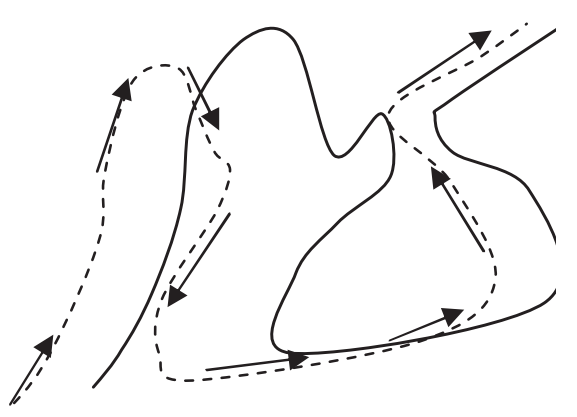

Рис. 1.2. - Збільшене зображення поверхні провідника

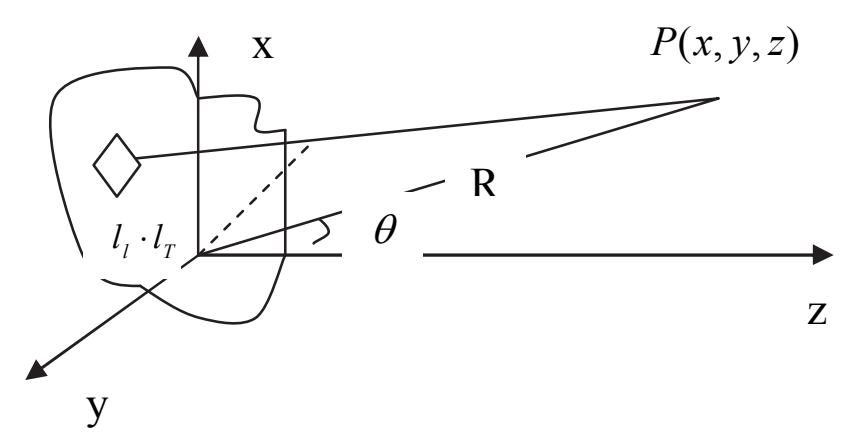

Рис. 1.3. - Траєкторія поширення сигналу від апертури антени до точки спостереження $P(x, y, z)$

У випадку спрямованого випромінювання радіосигналу антеною довільної апертури із площею $S^{*}$ фрактальної розмірності, результуюче поле у точці спостереження $P(x, y, z)$, в кожний конкретний момент часу, розраховується шляхом інтегрування елементарних елементів випромінювання на майданчику $l_{l} \cdot l_{T}$ за всією площею апертури з відповідним розподілом $G(\xi, \eta)$ і виражається рівнянням [11]: 


$$
F(P)=\frac{1}{4 \pi} \int S^{\prime} 1 G_{(\xi, \eta)} \frac{e \frac{-i k r}{1}}{r}\left[\left(i k+\frac{1}{r}\right) \cos (n, r)+i k \cos (n, S)\right] l_{L} l_{T},
$$

де $G(\xi, \eta)$ - розподіл поля в площині апертури; $(n, r)$ - кут між нормаллю до площини апертури й напрямком $r ;(n, S)$ - кут між нормаллю до площини апертури й вектором. Пойтинга поля на апертурі:

$$
k=\frac{2 \pi}{\lambda}
$$

$\lambda$ - довжина хвилі.

Однак слід зазначити, що практично всі апертури мають індивідуальні «рельєфи», привласні тільки їм. Тому в точці спостереження $P(x, y, z)$, у кожний конкретний момент часу, сигнал реалізується різними елементарними ділянками даного «рельєфу» і площа $S^{*}$, з якої відбувається випромінювання, із часом змінюється за законом, заданим «рельєфом» апертури антени. В свою чергу, зміна площі $S^{*}$ спричиняє модуляцію сигналу за амплітудою на інтервалі часу, відповідному до тривалості імпульсу, випромененого з поверхні, площа якої має фрактальну розмірність.

У даному випадку модулююча функція $u_{M}(t) \epsilon$ складною функцією часу та відповідає функції $S^{*}(t)$. Аналітичний вираз АМ-сигналу правомірно податі у вигляді [12]:

$$
S_{\mathrm{AM}}(u M, t)=A_{0}\left[1+m_{\mathrm{AM}} u_{M}(t)\right] \cos \left(w_{0}+\Psi_{0}\right)
$$

Спектр АМ-сигналу при такому модулюючому впливі якісно визначається тим, що будь-який складний сигнал $u_{\mathrm{M}}(t)$ можна податі у вигляді скінченної (чи нескінченної) суми гармонічних складових, якщо скористатись для цього рядом чи інтегральним перетворенням Фур'є.

Кожна гармонічна складова сигналу $u_{\mathrm{M}}(t)$ з частотою $\Omega_{i}$ сприяє появі в спектрі АМ-сигналу двох бічних складових з частотами $f_{0} \pm F_{i}$, а множина гармонічних складових модулюючого сигналу $\sum F_{i}-$ множині бічних складових з частотами $\sum\left(f_{0} \pm F_{i}\right)$. Такі перетворення спектра наведені на рис.1.4.

3 цього рисунка видно, що в спектрі сигналу, крім складової з частиною переносника $f_{0}$, містяться групи верхніх $\left(f_{0}+F\right)$ та нижніх $\left(f_{0}-F\right)$ бічних коливань, що утворюють відповідно верхню та нижню бічні смуги частот АМсигналу. При цьому верхня бічна смуга частот є масштабною копією як дискретного, так і неперервного спектра модулюючого сигналу, зсунутого за частотою на величину $f_{0}$. Нижня бічна смуга частот також повторює спектральну діаграму 
(спектральну щільність) сигналу $u_{\mathrm{M}}(t)$, алі з дзеркальним розташуванням частот (у зворотному порядку) відносно частоти переносника $f_{0}$. Ширина спектра даного АМ-Сигнулу $F_{\mathrm{AM}}$ дорівнює подвоєному значенню максимальної частоти $F_{\max }$ зміни $S^{*}$ в інтервалі часу випромінювання сигналу, тобто:

$$
F_{\text {AM }}=2 F_{\text {max }}
$$

3 цього виразу випливає, що амплітуда модульованого сигналу змінюється від $A_{\min }=A_{0}(1-m)$ до $A_{\max }=A_{0}(1+m)$, а потужність сигналу - від $P_{\min }=P_{\mathrm{H}}(1-$ $m)^{2}$ до $P_{\max }=P_{\mathrm{H}}\left(1+m^{2}\right)$, де $P_{H}=\frac{A_{0}^{2}}{2}-$ потужність несучого коливання. Середня потужність АМ-Сигналу дорівнює:

$$
P_{\text {cep }}=\frac{A_{0}^{2}}{2 T} \int_{0}^{T}(1+m \cos \Omega t)^{2} d t=P_{H}\left(1+\frac{m^{2}}{2}\right) \text {. }
$$

При $m=1 P_{\max }=4 P_{\mathrm{H}}$, а $P_{\text {cep }}=1,5 P_{\mathrm{H}}$; відношення середньої потужності до максимальної дорівнює 0,375, що свідчить про суттєвий недолік амплітудної модуляції - погане використання потужності передавача.

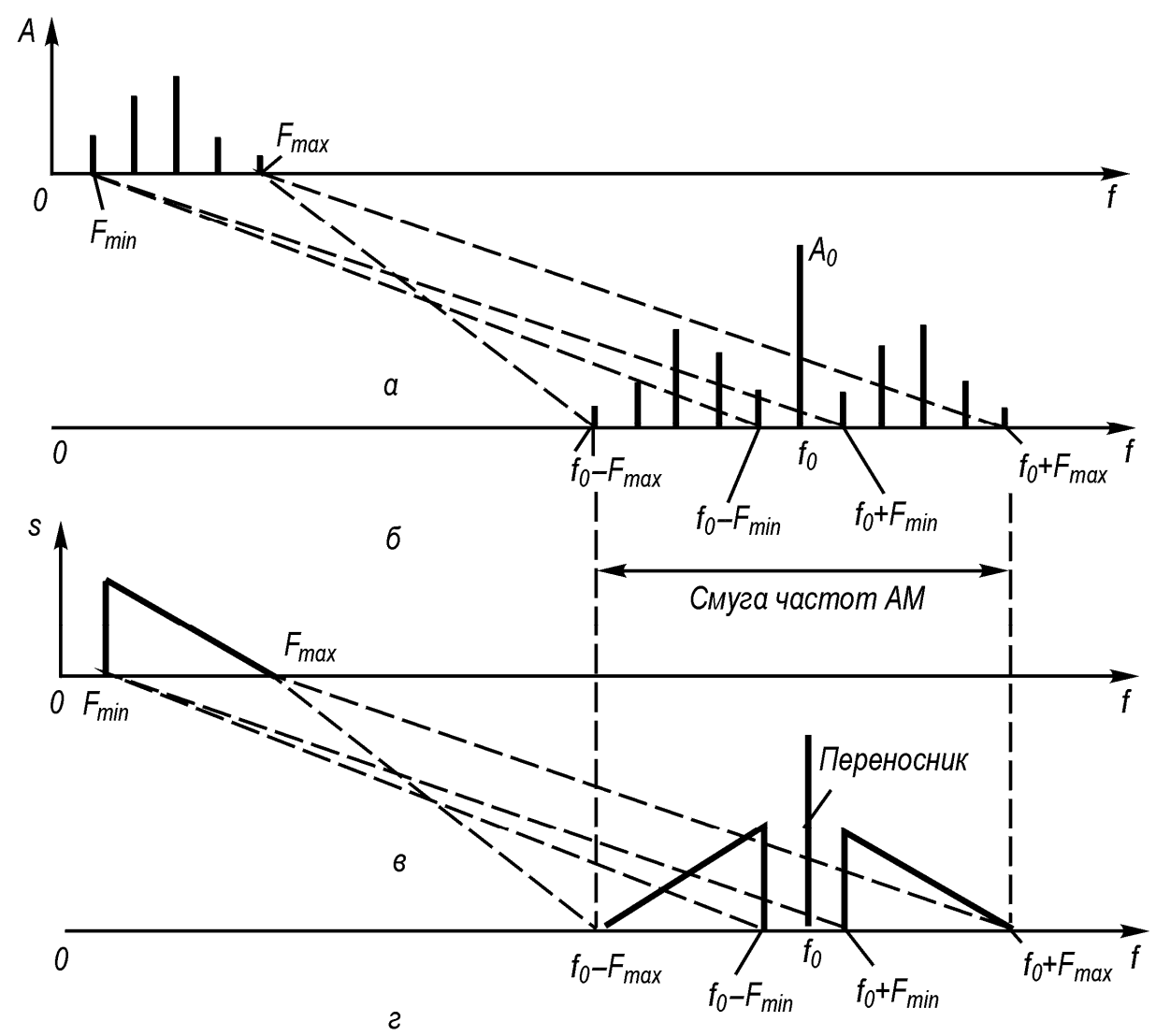

Рис. 1.4. Спектральні діаграми: $a$-закон зміни $S^{*}(t) ; \sigma-$ АМ-сигналу для багатоканальної модуляції; в - функції модуляції з неперервним спектром; 2- АМ-сигналу для модуляції функцією з неперервним спектром 
Значення ширини бічної смуги АМ сигналу в даному випадку залежить від частоти несучого коливання та смуги частот зміни $S^{*}(t)$. У звязку з тим, що практично всі апертури мають індивідуальні «рельєфи», привласні тільки їм, то інформація про значення ширини бічних смуг таких АМ сигналів, промодульованних за законами зміни $S^{*}(t)$ апертур конкретних антен, дозволяє проводити селекцію.

Однак дані коливання вимагають значного посилення для їхнього подальшого аналізу. В звязку з цим, розглянемо випадок, коли частота випроміненого зондуючого сигналу дорівнює (кратна) частоті власних коливань елементарних частинок речовини, з якої виготовляється антена. Цей випадок характеризується тим, що механічні коливання кристалічної структури речовини, що розглядається, не мають внутрішнього опору, тобто відсутня амортизація. Електричні властивості еквівалентних коливальних контурів кристалічної решітки відповідають тому, що опір $R=0$; це означає відсутність внутрішнього опору ланок.

Рівняння суміші сигналів взаємодії опромінення з коливальною структурою радіопоглинаючого матеріалу має наступний вигляд:

$$
U(t)=x(t) A \sin (\omega t+\varphi),
$$

де $x$ - лінійне відхилення атома від позиції в кристалічній решітці; $t$ - час; $A-$ амплітуда сигналу опромінення; $\varphi$ - початкова фаза електромагнітних коливань; $\omega$ - частота сигналу опромінення.

Для результуючого значення резонансного сигналу взаємодії [13] рішення рівняння (21), що задовольняє початковим умовам: $t=0, x=x_{0}=0$, буде мати вигляд:

$$
x_{\text {peз }}(t)=\frac{A}{K\left(K^{2}-\omega^{2}\right)}(-\omega \sin K t+K \sin \omega t),
$$

де $K$ - частота власних коливань кристалічної решітки.

Вираз у дужках рівняння (22) представляє собою суму двох гармонійних коливань: власних, з частотою $K$ :

$$
x_{c}(t)=\frac{A}{K^{2}-\omega^{2} k} \frac{\omega}{k} \sin K t
$$

та вимушених з частотою $\omega$ :

$$
x_{B}(t)=-\frac{A}{K^{2}-\omega^{2}} \sin \mathrm{K} t
$$

На рис. 1.5 схематично наведений характер коливань для випадку, коли $K>>\omega$.

Під час короткотермінової резонансної взаємодії процес характеризується залежністю $e^{-n t}(n-$ число кратності частот взаємодіючих коливань) і буде являти 
собою затухаючі коливання. Це характерно для опромінення імпульсними сигналами. За умови достатньо великого часу взаємодії, наприклад, при опроміненні квазібезперервним НВЧ-сигналом, характер резонансної взаємодії буде описуватися виразом:

$$
x(t)=\frac{A}{\left(K^{2}-\omega^{2}\right)^{2}+4 n^{2} \omega^{2}}\left(\left(K^{2}-\omega^{2}\right)^{2} \sin \omega t-2 n \omega K \cos \omega t\right)
$$

Параметри адитивного сигналу суміші визначиться як:

$$
\begin{gathered}
U(t)=\left(A^{2}+X^{2}+2 A x \cos (k-\omega) t+\Delta \varphi\right)^{\frac{1}{2}}, \\
\varphi(t)=\operatorname{arctg}\left(A \sin \omega t+\frac{x \sin k t}{A \cos \omega t}+X \cos k t\right),
\end{gathered}
$$

а частота биття багатотонального сигналу визначиться у вигляді:

$$
\omega_{\sigma}(t)=A^{2} \omega+X^{2} k+A X(\omega+k) \cos ((k-\omega) t+\Delta \varphi) / A^{2}+X^{2}+2 A x \cos ((k-\omega) t+\Delta \varphi)
$$

Якщо ввести позначення:

$$
\frac{A\left(K^{2}-\omega^{2}\right)}{\left(K^{2}-\omega^{2}\right)+4 n^{2} \omega^{2}}=M \cos \delta, \frac{2 A n \omega}{\left(K^{2}-\omega^{2}\right)+4 n^{2} \omega^{2}}=M \sin \delta,
$$

де $\frac{A}{\left(K^{2}-\omega^{2}\right)+4 n^{2} \omega^{2}}$, то рішення рівняння (25) можна записати як:

$$
x(t)=\frac{A \sin (\omega t-\delta)}{k\left(\left(1-\frac{\omega^{2}}{K^{2}}\right)^{2}+4 n^{2} \frac{\omega^{2}}{K^{4}}\right)^{\frac{1}{2}}}
$$
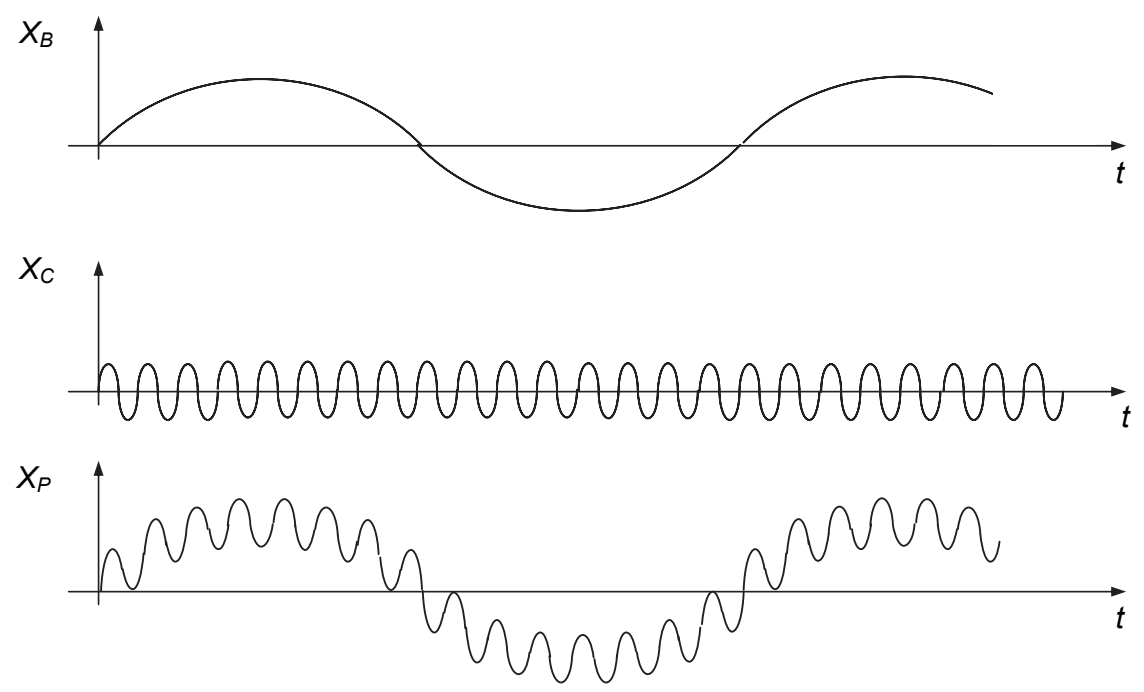

Рис. 1.5. - Модуляція власних коливань кристалічної решітки вимушеними коливаннями 
Для випадку резонансної взаємодії, як по частоті так і по фазі вираз (21) в операторному вигляді можна записати так:

$$
x(p)\left(p^{2}+K^{2}\right)=\frac{A K}{p^{2}+K^{2}},
$$

де $x(p)=\frac{A K}{\left(p^{2}+K^{2}\right)^{2}}$

причому $p$ - оператор Лапласа.

Зображення (27) є правильна раціональна дріб, початкова функція якої має вигляд:

$$
\frac{K}{p^{2}+K^{2}}=\int_{0}^{\infty} e^{-p t} \sin K t d t
$$

Після проведення диференціювання обох частин рівняння (27) за $K$, представивши інтеграл правої частини рівняння у вигляді суми двох інтегралів дійсної змінної, кожна з яких залежить від параметра $K$ :

$$
\frac{1}{p^{2}+K^{2}}-\frac{2 K^{2}}{\left(p^{2}+K^{2}\right)}=\int_{0}^{\infty} e^{-p t} t \cos K t d t
$$

Використовуючи рівняння (28), вираз (29) можна записати у вигляді:

$$
-\frac{2 K^{2}}{\left(p^{2}+K^{2}\right)^{2}}=\int_{0}^{\infty} e^{-p t}\left(t \cos K t-\frac{1}{K} \sin k t\right) d t .
$$

3 (30) витікас, що:

$$
\frac{A K}{\left(p^{2}+K^{2}\right)^{2}}=\frac{A}{2 K}\left(\frac{1}{2} \sin K t-t \cos K t\right) .
$$

Виходячи з цього, сигнал резонансної взаємодії опромінюючого й власного електромагнітного коливання буде описуватися виразом [14]:

$$
x_{\text {pe3 }}(T)=\frac{A}{2 K}\left(\frac{1}{K} \sin \mathrm{K} T-T \cos \mathrm{K} T\right),
$$

де $T=t+\Delta t-$ час запізнення формування сигналу відгуку і визначається як $d \varphi / d \omega_{\text {рез. }}$

Таким чином, при кратності частот опромінюючого сигналу і частоти внутрішніх коливань кристалічної структури провідника амплітуда результуючого резонансного сигналу випромінення буде збільшуватися в $2 A^{2}$ раз, а внутрішній опір провідника $R \rightarrow 0$; під час збільшення часу резонансного опромінення $(t \rightarrow \infty)$ амплітуда результуючого резонансного сигналу необмежено зростає $\left(A_{\text {рез }} \rightarrow \infty\right)$ за умови не тільки частотного, але і фазового резонансу. Це дозволяє реалізувати фрактально-резонансну селекцію сигналу шляхом аналізу ширини бічної смуги частот його амплітудного спектру в точці прийому. 


\section{Список використаних джерел}

1. Bate H. П.. Schmidt P. №.. Phvs. Rev. Lett., 53, 5\% (1984).

2. Stapleton H. /., Allen J. P., Fltjnn C. P., Stlnson D. G., Kurtz S. R.. Phys Rev. Lett. 45. $1456(1080)$.

Allen J. P., Colvin J. T., Stlnson D. G., Flynn C. P., Stapleton H. J., Biophvs. J, 38. 299 (1982).

3. Helman /. 5.. Conlrlio A., Tsallls C., Phys. Rev. Lett.. 53. 1185 (1984); 54. 1735 (1985).

4. Franco H, Bossu J.. Godfrin H.. Cryogenics, September 1984, p. 477.

5. Allen A /. Schofield P.. preprint (1985). будет опубликовано и Proc NATO meeting on Scaling Phenomenon in Disordered System. Geilo. April 1985. Plenum.

6. Pfeijer P., Avnir П., J, Chem. Phys., 79. 3558 (1983).

Avnlr D.. Farln D . Pfeifer P., J. Chem. Phys., 79, 3566 (1983); Nature (London). 308. 261 (1984).

7. Tsallis C., Caride A. O.. Bollint C. G.. Glambiagi J J . Helman J. S.

8. Dillon I, P . Rapp R F... Vllches O. F.., J. Low Temp. Phyt., 59.35 (1985). Rapp R. £., Dillon L D.. Godfrin //.. Cryogenics. 25. 152 (1985).

9. Alexander S, Orbach R.. J Physique Lett.. 43. L625 (1982).

10. Jackson J. D., Classical Electrodynamics. 2nd edition, J. Wiley and Sons 1975.

11. Справочник по радиолокации. Под ред. М. Сколника. Нью-Йорк, 1970. Пер. с англ. (в четырех томах) под общей ред. К.Н. Трофимова. Том. 2. Радиолокационные антенные устройства. Под ред. П.И. Дудника. М., «Сов. радио», 1977, 408 с.

12. В.К. Стеклов, Л.Н. Беркман. Теорія електричного зв'язку. За редакцією д-ра техн. наук, проф. В.К. Стеклова. Київ. «Техніка». 2006.

13. Дорохов А.П. Расчет и конструирование антенно-фидерных устройств. Х.: ХГУ, 1960. - 284 с.

14. Пархомей I. Р., Толюпа С. В., Дружинін В. А. Резонансні методи отримання і використання інформації в радіотехнології. К.: Видавництво ДУІКТ, 2011. - 213 с. 